\title{
Microwave Derived Nano Sized Zirconium Vanadate as an Adsorbent for Heavy Metal Ions
}

\author{
Arunkumar Lagashetty $^{1 *(D)}$, Sangappa K Ganiger ${ }^{2}$ (D), Shashidhar Reddy ${ }^{3}$ (D) \\ Department of Studies in Chemistry, Vijayanagara Sri Krishnadevaraya University, Ballari-583105 Karnataka, India \\ Department of Physics, Government Engineering College, Raichur-584135, Karnataka, India; skg7385@ gmail.com; \\ Department of Chemistry, S.D.M College of Engineering and Technology, Dharwad, 580002 Karnataka, India; \\ shashidhar66111@gmail.com; \\ * Correspondence: arun.lagashetty@gmail.com;
}

Scopus Author ID 35608190300

Received: 17.06.2020; Revised: 4.07.2020; Accepted: 5.07.2020; Published: 8.07.2020

\begin{abstract}
Bimetallic metal oxide nanomaterials are synthesized by microwave combustion route encourage to the synthetic chemists because of its simplicity. Microwave burning of single-phase oxide materials with polymer as fuel to form its multiphase nanomaterials. Nanosized Zirconium vanadate $\left(\mathrm{ZrV}_{2} \mathrm{O}_{7}\right)$ material is prepared by self-propagating combustion methods using a polymer as a fuel. Zirconium oxide $\left(\mathrm{ZrO}_{2}\right)$ and vanadium pentoxide $\left(\mathrm{V}_{2} \mathrm{O}_{5}\right)$ with polyvinyl alcohol were ignited in an open atmosphere and complete burning in a microwave oven for about 15 minutes to form a zirconium vanadate sample. Adsorption study of heavy metal ions like lead and mercury ions on the prepared sample is well studied. The structure of as-prepared $\mathrm{ZrV}_{2} \mathrm{O}_{7}$ and its adsorbed sample was well studied by employing a powder X-ray diffraction (XRD) tool. The morphology of as-prepared $\mathrm{ZrV}_{2} \mathrm{O}_{7}$ and adsorbed sample material was studied by Scanning Electron Micrograph (SEM) tool. Fourier Transform Infrared (FTIR) spectral study was undertaken to know the bonding in the prepared zirconium vanadate nanomaterials. Further, the adsorption study of heavy metal ions on the $\mathrm{ZrV}_{2} \mathrm{O}_{7}$ sample is also undertaken at room temperature.
\end{abstract}

Keywords: Zirconium oxide; Zirconium Vanadate; Vanadium pentoxide; XRD; SEM; IR.

(C) 2020 by the authors. This article is an open-access article distributed under the terms and conditions of the Creative Commons Attribution (CC BY) license (https://creativecommons.org/licenses/by/4.0/).

\section{Introduction}

Ceramics synthesis through the microwave-assisted route is gaining much importance due to its simplicity and enhance reaction rate [1-2]. It is also an eco-friendly system with a complete energy transfer system [3-4]. Direct irradiation of the reaction mixture to the microwaves forms the homogeneity by direct burning. The way of preparation counts a lot to obtain stoichiometric phases of metal oxides [5-6]. The structures and properties of oxide materials strongly depend upon the conditions of synthesis. The solid-state reaction by grinding and calcination produces the perfect phase using polymer fuel [7-8]. Zirconium vanadate shows high thermal expansion property and high specific capacity, hence they are used as storage materials. However, the capacity retention is reduced (about $61 \%$ ), and this may be due to the lower electronic conductivity and large crystallite size [9-10]. Therefore, a new strategy is required to develop $\mathrm{ZrV}_{2} \mathrm{O}_{7}$ to enhance the electrical conductivity and thereby improve capacity retention, and electrochemical reversibility as the preparation methods, morphology, porosity, crystallite size, and aspect ratio can significantly affect the electrochemical performance [11-12]. 
Zirconium vanadate $\left(\mathrm{ZrV}_{2} \mathrm{O}_{7}\right)$ nanomaterials are prepared by using zirconium oxide, and vanadium pentoxide employing microwave-assisted route is reported in the present work. Polyvinyl alcohol is used as a fuel for the conversion of zirconium oxide and vanadium pentoxides into its zirconium vanadate nanomaterials. Initially, the combustion process is initiated by burning on an electric oven. Then combustion treatment is given for the complete conversion of samples into zirconium vanadate nanomaterials. The prepared sample is well characterized for its structure by X-ray diffraction (XRD), morphology by Scanning Electron Microscope (SEM), and bonding by Fourier Transform Infrared study (FT-IR) techniques. Adsorption study of zirconium vanadate for heavy metal ions like lead and mercury is also undertaken for adsorption behavior.

\section{Materials and Methods}

\subsection{Synthesis of Zirconium Pyrovanadate.}

\subsubsection{Materials and methods.}

Zirconium oxide, Vanadium pentoxide, and polyvinyl alcohol chemicals are used in the present study were of AR (Analytical Reagent) grade. Polyvinyl alcohol is used as fuel for the combustion reaction, and microwave-assisted combustion method is adopted for the synthesis of $\mathrm{ZrV}_{2} \mathrm{O}_{7}$ nanomaterials.

\subsubsection{Preparation of $\mathrm{ZrV}_{2} \mathrm{O}_{7}$ nanomaterials.}

Nanosized Zirconium oxide $\left(\mathrm{ZrO}_{2}\right)$ and vanadium pentoxide $\left(\mathrm{V}_{2} \mathrm{O}_{5}\right)$ materials are prepared according to the literature method [13-14]. An equimolar quantity of zirconium oxide and vanadium pentoxide was ground well with polyvinyl alcohol in the ratio of 1:1:5 in a pestle and mortar [15-16]. The resultant mixture was transferred into a crucible and was burnt on an electric oven for complete evaporation of fumes. Then, it is transferred to a microwave oven for complete calcination. The sample is calcined on a microwave oven having $2.45 \mathrm{GHz}$ frequency, and power is $800 \mathrm{w}$ for about 15 minutes. During burning, the approximate temperature of the reaction may be around $400^{\circ} \mathrm{C}$. The reaction mixture burns and leaving behind a solid zirconium vanadate crystalline product. Following is the possible reaction taking place in the above process, and the synthetic scheme is given in scheme 1 . The initial burning, burning in microwave woven, and the obtained zirconium vanadate is shown in figure 1.

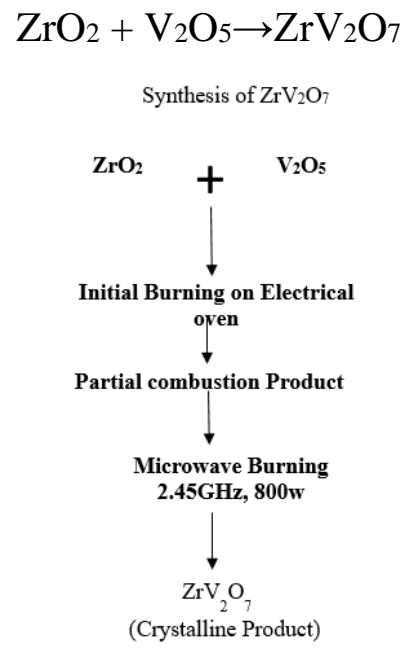

Scheme 1. Synthesis of Zirconium Vanadate. 


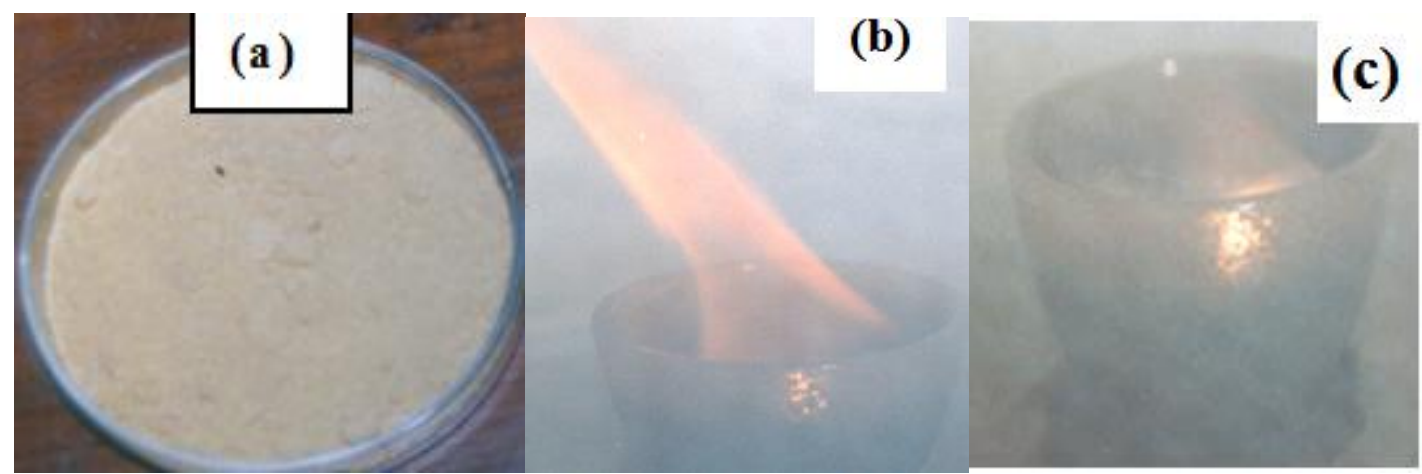

Figure 1. (a) $\mathrm{ZrV}_{2} \mathrm{O}_{7}$ sample (b) Observed flame during combustion (c) Microwave burning.

\subsubsection{Adsorption study.}

The lead acetate solution (200 ppm) is prepared in double-distilled water. Known volume $(25 \mathrm{ml})$ of the solution is taken in a small column containing $0.5 \mathrm{~g}$ of the prepared zirconium vanadate sample supported by cotton wool. This column is kept for 24 hours for complete adsorption. The eluent solution is taken out and is subjected to an atomic absorption study (AAS). The adsorbed sample is dried under room temperature and is subjected to structural, morphological, and bonding characterization to know the adsorption lead ions on the zirconium vanadate adsorbent. Similar experimentation is carried out for mercury metal ions on the zirconium vanadate sample

\subsubsection{Characterization.}

The structures of as prepared zirconium vanadate were studied by X-ray diffraction using $X^{\prime}$ Pert Pro X-ray diffractometer with $\mathrm{Cu} \mathrm{K \alpha}$ as source of radiation in a $\theta-2 \theta$ configuration. JEOL JSM-6380 LA Scanning electron microscope with energy dispersive microanalysis of X-Ray (EDAX) is used to study particle morphology with metal confirmation of the sample. TEM images are carried out using the Technai-20 Philips transmission electron microscope. The transmission electron microscope was operated at $190 \mathrm{KeV}$.

\section{Results and Discussion}

\subsection{X-ray diffraction.}

The X-ray powder pattern of Zirconium vanadate is shown in Figure 2. It is found to be crystalline, exhibiting the cubic phase, and is in good agreement with JCPDS No. 01-088 0587. Unit cell parameters ware obtained by the least-square refinement of the powder XRD data. This study reveals that the sample is monophasic with a cubic spinel structure having nanosized particles [17-18].

\subsection{Scanning Electron Microscopy (SEM).}

Figure 3 shows SEM image of an as-prepared zirconium vanadate sample. This image shows, particles are in the nano range, and most of the particles are spherical with a selfassembled compact structure. In addition to this, some particles are irregular shapes with a selfassembled arrangement due to crystalline behavior [19-20]. 




Figure 2. XRD pattern of the $\mathrm{ZrV}_{2} \mathrm{O}_{7}$ sample.

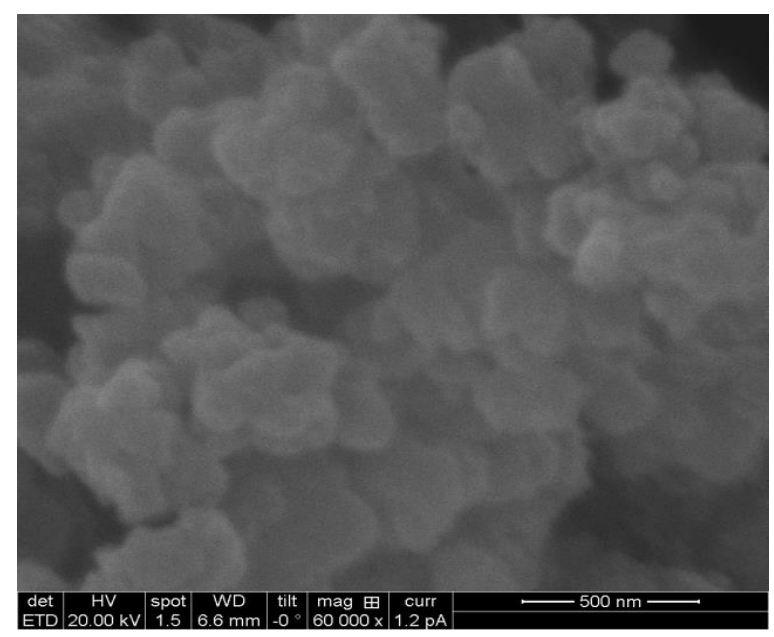

Figure 3. $\mathrm{SEM}$ image of the $\mathrm{ZrV}_{2} \mathrm{O}_{7}$ sample.

\subsection{EDX Study.}

EDX analysis is carried out to know the presence of elements in the prepared sample. Figure 4 shows EDX pattern of the combustion derived $\mathrm{ZrV}_{2} \mathrm{O}_{7}$ sample. The pattern shows the presence of $\mathrm{Zr}, \mathrm{V}$, and $\mathrm{O}$ at respective positions confirms the purity of the sample.

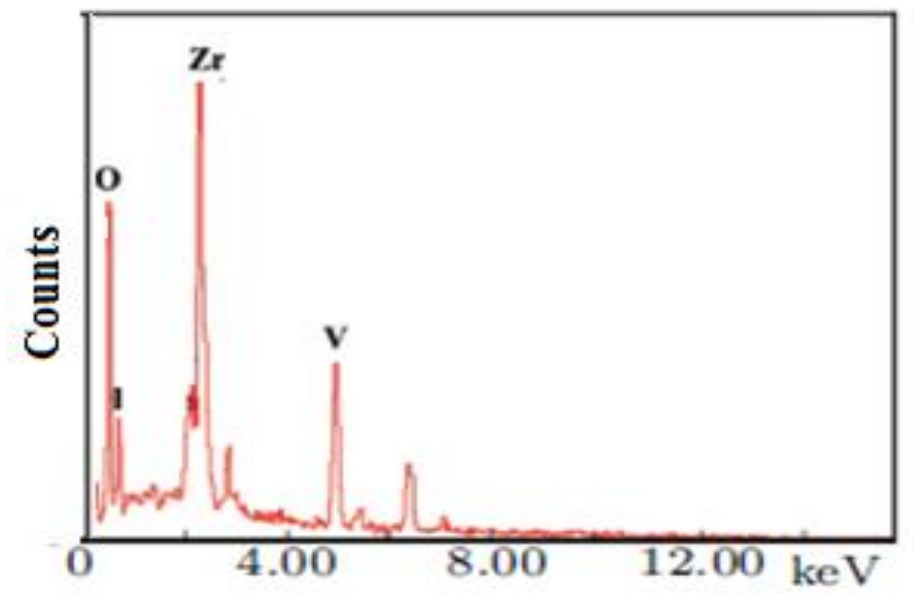

Figure 4. EDX pattern of the $\mathrm{ZrV}_{2} \mathrm{O}_{7}$ sample. 


\subsection{Infrared Study.}

Figure 5 shows the FT-IR spectrum of an as-prepared zirconium vanadate sample. The metal-oxygen bonding and nature of the synthesized zirconium vanadate sample were carried out by the infrared study. Metal oxides generally give absorption bands below $1000 \mathrm{~cm}^{-1}$ arising from inter-atomic vibrations [21]. The peak $3300 \mathrm{~cm}^{-1}$ corresponds to the water of absorption-vibration frequency at $1050 \mathrm{~cm}^{-1}$ due to the presence of some overtones. Peaks below $1000 \mathrm{~cm}^{-1}$ correspond to Metal-oxygen vibrational modes of the sample confirm the formation of zirconium vanadate [22].

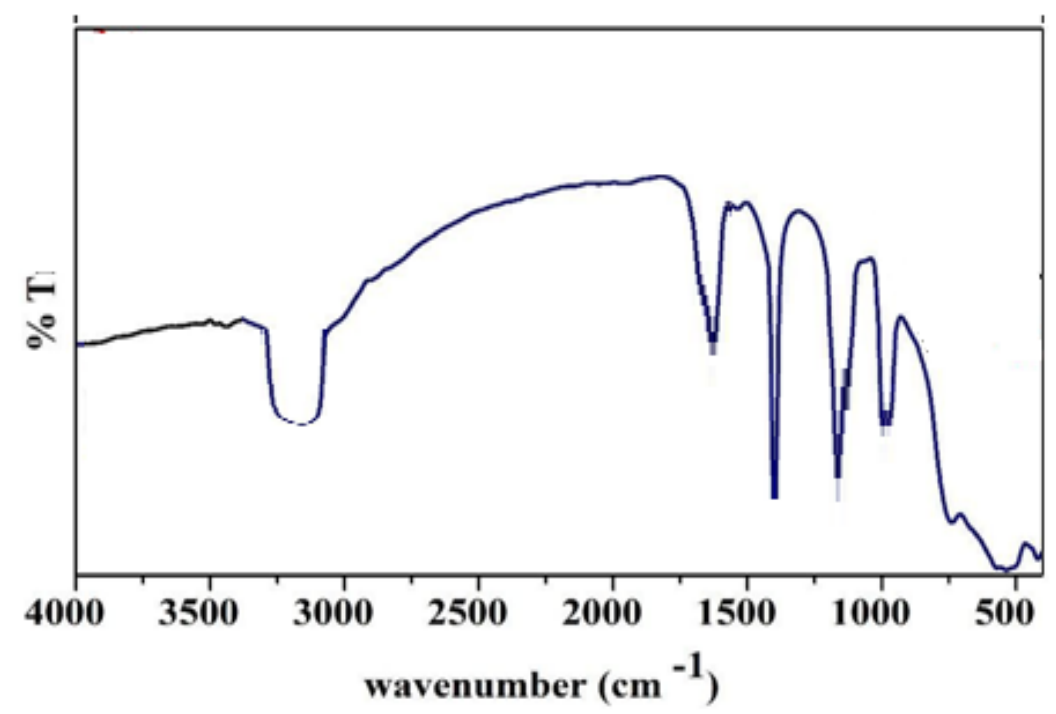

Figure 5. FT-IR spectrum of the $\mathrm{ZrV}_{2} \mathrm{O}_{7}$ sample.

\subsection{TEM Study.}

Figure 6 shows the TEM image of the prepared zirconium pyrovandate sample. The image shows fine particles with the crystalline nature of the sample. Particles with complexibility formation with dense structure can be viewed in the image. The irregular shape and varied sized particles are falls under the nano range. In some parts, it may be found that close agglomeration with the compact is also observed, which may be an applicable morphology as a good adsorbent for metal ions.

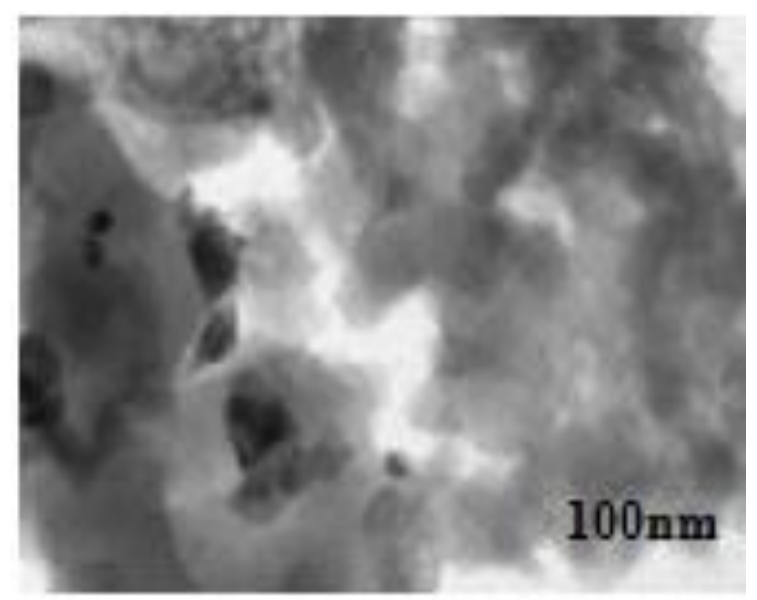

Figure 6. TEM image of the $\mathrm{ZrV}_{2} \mathrm{O}_{7}$ sample. 


\subsection{Adsorption Study.}

Table 1 shows AAS results of pure lead and mercury solutions with fluent lead and mercury solutions after adsorption. It is clearly observed from the table that, the reduction in the concentration of eluent lead and mercury solution in comparison with plane lead and mercury solution confirms the loss of lead and mercury ions by adsorption on zirconium vanadate sample. This sample shows considerable adsorption due to remarkable adsorption active sites present on the sample [23]. Adsorption study reveals that the prepared metal oxide sample acts as good adsorbents for heavy metal ions.

Table 1. AAS results of lead and mercury adsorption on the $\mathrm{ZrV}_{2} \mathrm{O}_{7}$ sample.

\begin{tabular}{c|c|c|c} 
Sl. No & Concentration & $\begin{array}{c}\text { Concentration of } \\
\mathbf{P b}^{\mathbf{2}+} \text { solution }\end{array}$ & $\begin{array}{c}\text { Concentration of } \mathbf{H g}^{\mathbf{2}} \\
\text { solution }\end{array}$ \\
\hline 1 & Initial Concentration & 200 & 200 \\
\hline 2 & Concentration After passing through $\mathrm{ZrV}_{2} \mathrm{O}_{7}$ sample & 120 & 130
\end{tabular}

\section{Conclusions}

A combustion route with polyvinyl alcohol fuel is used for the successful synthesis of the zirconium vanadate sample. This solid-state reaction achieved the phase formation of an oxide sample with simple experimentation. Adsorption study concludes that the prepared sample acts as a good adsorbent for heavy metal ions.

\section{Funding}

This research received no external funding.

\section{Acknowledgments}

Authors thank DST-FIST (SR/FST/CSI-003/2016) grant provided for instruments and infrastructure facilities. Thanks are due to Prof. A.Venkataraman, Professor, Department of Chemistry, Gulbarga University, Kalaburagi, Karnataka, India, for useful discussion in spectral analysis.

\section{Conflicts of Interest}

The authors declare no conflict of interest.

\section{References}

1. Brahma, S.; Liu, C.P.; Shivashankar, S.A. Microwave irradiation assisted, one pot synthesis of simple and complex metal oxide nanoparticles: a general approach. Journal of Physics D: Applied Physics 2017, 50.

2. Aivazoglou, E.; Metaxa, E.; Hristoforou, E. Microwave-assisted synthesis of iron oxide nanoparticles in biocompatible organic environment. AIP Advances 2017, 8, http://doi.org/10.1063/1.4994057.

3. Hamelian, M.; Varmira, K.; Veisi, H. Green synthesis and characterizations of gold nanoparticles using Thyme and survey cytotoxic effect, antibacterial and antioxidant potential. Journal of Photochemistry and Photobiology B: Biology 2018, 184, 71-79,https://doi.org/10.1016/j.jphotobiol.2018.05.016.

4. Rodrigues, B.S.; Branco, C.M.; Corio, P.; Souza, J.S. Controlling Bismuth Vanadate Morphology and Crystalline Structure through Optimization of Microwave-Assisted Synthesis Conditions. Crystal Growth \& Design 2020, 20, 3673-3685,https://doi.org/10.1021/acs.cgd.9b01517.

5. Ceballos-Chuc, M.C.; Ramos-Castillo, C.M.; Alvarado-Gil, J.J.; Oskam, G.; Rodríguez-Gattorno, G. Influence of Brookite Impurities on the Raman Spectrum of $\mathrm{TiO} 2$ Anatase Nanocrystals. The Journal of Physical Chemistry C 2018, 122, 19921-19930,https://doi.org/10.1021/acs.jpcc.8b04987.

6. Ashraf, H.; Anjum, T.; Riaz, S.; Naseem, S. Microwave-Assisted Green Synthesis and Characterization of Silver Nanoparticles Using Melia azedarach for the Management of Fusarium Wilt in Tomato. 2020, 11, 1221, https://doi.org/10.3389/fmicb.2020.00238. 
7. Aritonang, H.F.; Koleangan, H.; Wuntu, A.D. Synthesis of silver nanoparticles using aqueous extract of medicinal plants' (Impatiens balsamina and Lantana camara) fresh land analysis of antimicrobial activity. International Journal of Microbiology 2019, 2019,https://doi.org/10.1155/2019/8642303.

8. Al-Haddad, J.; Alzaabi, F.; Pal, P.; Rambabu, K.; Banat, F. Green synthesis of bimetallic copper-silver nanoparticles and their application in catalytic and antibacterial activities. Clean Technologies and Environmental Policy 2020, 22, 269-277,https://doi.org/10.1007/s10098-019-01765-2.

9. Ganiger, S.K.; Murugendrappa, M.V. Lab Scale Study on Humidity Sensing and D.C. Conductivity of Polypyrrole/Strontium Arsenate (Sr3(AsO4)2) Ceramic Composites. Polymer Science, Series B 2018, 60, 395-404, https://doi.org/10.1134/S1560090418030119.

10. Bashir, A.; Malik, L.A.; Dar, G.N.; Pandith, A.H. Microwave-Assisted Hydrothermal Synthesis of Agglomerated Spherical Zirconium Phosphate for Removal of $\mathrm{Cs}+$ and $\mathrm{Sr} 2+$ Ions from Aqueous System.Applications of Ion Exchange Materials in the Environment2019, 65, 95-108, http://doi.org/10.1007/978-3-030-10430-6_5.

11. Fierascu, I.; Fierascu, I.C.; Brazdis, R.I.; Baroi, A.M.; Fistos, T.; Fierascu, R.C. Phytosynthesized Metallic Nanoparticles_-between Nanomedicine and Toxicology. A Brief Review of 2019's Findings. Materials 2020, 13, https://doi.org/10.3390/ma13030574.

12. Chand, K.; Cao, D.; Eldin Fouad, D.; Hussain Shah, A.; Qadeer Dayo, A.; Zhu, K.; Nazim Lakhan, M.; Mehdi, G.; Dong, S. Green synthesis, characterization and photocatalytic application of silver nanoparticles synthesized by various plant extracts. Arabian Journal of Chemistry 2020,12, 1-14, https://doi.org/10.1016/j.arabjc.2020.01.009.

13. Lagashetty, A.; Ganiger, S.K. Microwave-Assisted Synthesis, Characterization and Thermal study of Nano sized Metal Aluminates. J. Met. Mater. Sci.2018, 60, 139-148.

14. Taha, A.; Ben Aissa, M.; Da'na, E. Green Synthesis of an Activated Carbon-Supported Ag and ZnO Nanocomposite for Photocatalytic Degradation and Its Antibacterial Activities. Molecules 2020, 25,https://doi.org/10.3390/molecules25071586.

15. Sharma, D.; Kanchi, S.; Bisetty, K. Biogenic synthesis of nanoparticles: A review. Arabian Journal of Chemistry 2019, 12, 3576-3600,https://doi.org/10.1016/j.arabjc.2015.11.002.

16. Ulaeto, S.B.; Mathew, G.M.; Pancrecious, J.K.; Nair, J.B.; Rajan, T.P.D.; Maiti, K.K.; Pai, B.C. Biogenic Ag Nanoparticles from Neem Extract: Their Structural Evaluation and Antimicrobial Effects against Pseudomonas nitroreducens and Aspergillus unguis (NII 08123). ACS Biomaterials Science \& Engineering 2020, 6, 235-245,https://doi.org/10.1021/acsbiomaterials.9b0125.

17. Alenazi, B.; Alsalme, A.; Alshammari, S.G.; Khan, R.A.; Siddiqui, M.R.H. Ionothermal Synthesis of Metal Oxide-Based Nanocatalysts and Their Application towards the Oxidative Desulfurization of Dibenzothiophene. Journal of Chemistry 2020, 2020,21-28, https://doi.org/10.1155/2020/3894804.

18. Unuofin, J.O.; Oladipo, A.O.; Msagati, T.A.M.; Lebelo, S.L.; Meddows-Taylor, S.; More, G.K. Novel silverplatinum bimetallic nanoalloy synthesized from Vernonia mespilifolia extract: antioxidant, antimicrobial, and cytotoxic activities. Arabian Journal of Chemistry 2020,https://doi.org/10.1016/j.arabjc.2020.06.019.

19. Sharma, C.; Ansari, S.; Ansari, M.S.; Satsangee, S.P.; Srivastava, M.M. Single-step green route synthesis of $\mathrm{Au} / \mathrm{Ag}$ bimetallic nanoparticles using clove buds extract: Enhancement in antioxidant bio-efficacy and catalytic activity. Materials Science and Engineering: C 2020, 116, https://doi.org/10.1016/j.msec.2020.111153.

20. Jana, A.; Scheer, E.; Polarz, S. Synthesis of graphene-transition metal oxide hybrid nanoparticles and their application in various fields. Beilstein J Nanotechnol 2017, 8, 688-714, https://doi.org/10.3762/bjnano.8.74.

21. Lagashetty, A.; Patil, M.K.; Ganiger, S.K. Green Synthesis, Characterization, and Thermal Study of Silver Nanoparticles by Achras sapota, Psidium guajava, and Azadirachta indica Plant Extracts. Plasmonics 2019, 14, 1219-1226,https://doi.org/10.1007/s11468-019-00910-3.

22. Arunkumar Lagashetty,: Sangappa K. Ganiger,; Shashidhar. Synthesis Characterization and antibacterial study of $\mathrm{Ag}-\mathrm{Au} \mathrm{Bi}$-metallic nanocomposite by bioreduction using piper betle leaf extract, Heliyon 2019, 5 , e02794, https://doi.org/10.1016/j.heliyon.

23. Taha, A.; Ben Aissa, M.; Da'na, E. Green Synthesis of an Activated Carbon-Supported Ag and ZnO Nanocomposite for Photocatalytic Degradation and Its Antibacterial Activities. Molecules 2020, 25,https://doi.org/10.3390/molecules25071586. 